Research Article

\title{
Tensile Behaviour of Welded and Un-welded AA 6061 Alloy Sheet Comparing with Prediction Results
}

\author{
N. V. Narasimha Charyulu ${ }^{\dot{A}^{*}}$, B. Dheeraj Reddy ${ }^{\dot{A}}$, K. Thulasiswar Reddy ${ }^{\dot{A}}$, B. Gnanavi ${ }^{\dot{A}}$, S. Sushmitha ${ }^{\dot{A}}$ and Perumalla \\ Janaki Ramulu $^{\dot{A}}$
}

${ }^{\grave{A}}$ Department of Mechanical Engineering, Vardhaman College of Engineering, Shamshabad, Hyderabad, India

Accepted 10 January 2014, Available online 01 February 2014, Special Issue-2, (February 2014)

\begin{abstract}
In the present work, the mechanical behaviour of base metal, friction stir welded (FSW) sheet and only weld zone of FSW sheet has investigated and evaluated the properties namely flow strength, elongation and hardness. The experimental data was compared with simulation results for individual tensile behaviour of all the three sheets. Micro-hardness showed a decreasing trend, from the base material to the centre of the nugget zone, except near the transition zone. The FSW sheets showed a decreased flow stress and improved elongation when compared to base material.
\end{abstract}

Keywords: Friction stir welding; tensile properties; elongation; hardness; prediction.

\section{Introduction}

Friction stir welding (FSW) process has different process parameters like welding parameters, tool geometry, and joint design that affect the joint quality of material in a compounding fashion. Mishra and Ma (2005) reviewed about the process parameter effects on the FSW joint properties. It has been demonstrated that the tool geometry and welding parameters are effective in deciding the properties of weld region and to form perfect defect free welds. These defect free welds improve the microstructure and mechanical properties of FSW joints. Ghosh et al (2010) investigated about bond strength between two different materials namely wrought A356 and AA 6061T6 alloys by changing the process parameters. Most of the studies on FSW are focused to understand the process itself, especially the effect of process parameters on the quality of welding, mechanical properties, microstructures etc. There are many studies that are focused on the mechanical properties evaluation of friction stir welded sheets of different materials. Some of them are described in the present work.

Sato and Kokawa (2001) worked on AA 6063-T5 with $4 \mathrm{~mm}$ thickness, FSW was done at welding speed of 10 $\mathrm{mm} / \mathrm{s}$ using $15 \mathrm{~mm}$ shoulder diameter and examined the dominant microstructural factors governing the global tensile properties of the welded joint. In this work, weld was kept in transverse direction, i.e., perpendicular to the welding direction during the tensile test. It was observed that the minimum hardness and tensile properties were found in FSW joints. The tensile failure was seen in the minimum hardness region. Lim et al (2004) studied the tensile behavior of FSW AA 6061-T651 with $4 \mathrm{~mm}$ thickness plates at different rotation speeds and welding speeds. Tensile specimens were prepared in transverse direction. It was found that the elongation of FSW joints decreased with decreasing welding speed and increasing rotating speed. The yield strength and ultimate tensile strength were also influenced by these parameters.

Buffa et al (2007) investigated the application of the FSW process for the development of tailor welded blanks for their usage in the automotive industry. In this work, FSW was done on AA6016-T4 blanks of different thicknesses (1, 2, 2.4 and $3 \mathrm{~mm})$ and the local mechanical properties and the formability of the welded blanks were investigated and compared with laser welded parts. The mechanical properties of tailor welded blanks were evaluated with the weld perpendicular to the loading direction. In addition mechanical and metallurgical investigations were also observed on the welded joints. Results showed that FSW has better mechanical behavior and formability compared to laser welding. Elangovan and Similar studies were carried out by Simar et al (2008), Zadpoor et al (2009), Cerri et al (2010) on the mechanical behavior of AA 6005 material, dissimilar FSW joints made of AA 2024-T3, AA 7075-T6 and AA 2024-T3, AA 6082-T6 respectively.

Rajakumar et al (2011) investigated the tensile strength, hardness and corrosion rate of friction-stir-butt welded joints made of AA6061-T6 aluminum alloy. Empirical relationships were established between the FSW parameters like rotational speed, welding speed, axial force, shoulder diameter, pin diameter and tool hardness and the their responses on tensile strength, hardness and corrosion rate. They predicted the optimal welding conditions to maximize the tensile strength and minimize 
the corrosion rate. The tensile test samples were made in transverse direction for mechanical properties evaluation.

It is understood from the discussion made that most of the studies are aimed at analyzing the influence of FSW parameters on the microstructure, and mechanical behavior of FSW blanks characterized by tensile tests with samples having weld along transverse direction. These studies are focused on the evolution of mechanical properties, microstructure and defects with respect to the FSW parameters. The main aim of the present work is the mechanical behaviour of base metal, friction stir welded (FSW) sheet and only weld zone of FSW sheet has investigated and evaluated the properties namely flow strength, elongation and hardness. The experimental data was compared with simulation results for individual tensile behaviour of all the three sheets.

\section{Experimental procedure}

\subsection{Base Material}

Aluminum alloy 6061-T651 of similar gage, $2.1 \mathrm{~mm}$, is used for welding experiments. It is formable enough to manufacture stamped parts. 'Table 1' shows the chemical composition of this material.

Table 1 Chemical composition of AA 6061-T651 base metal (in wt. \%)

\begin{tabular}{|l|l|l|l|l|l|l|l|l|}
\hline $\mathrm{Si}$ & $\mathrm{Fe}$ & $\mathrm{Cu}$ & $\mathrm{Mn}$ & $\mathrm{Mg}$ & $\mathrm{Cr}$ & $\mathrm{Zn}$ & $\mathrm{Ti}$ & $\mathrm{Al}$ \\
\hline 0.65 & 0.3 & 0.27 & 0.02 & 1.0 & 0.17 & 0.04 & 0.02 & Balance \\
\hline
\end{tabular}

\subsection{Welding experiments}

Same thickness sheets were welded together using friction stir welding machine. This machine has designed and developed by IISc and ETA Technologies and it has a unique capability in that the plunge depth, rotational speed, or welding speed could be varied with a test. The tool rotational speed of $1500 \mathrm{rpm}$, welding speed of 120 $\mathrm{mm} / \mathrm{min}$ and plunge depth of $1.95 \mathrm{~mm}$ parameters were considered for welding, while the tool tilt angle $\left(2.5^{\circ}\right)$ was kept constant throughout the process. The tool was made of hot die steel (HDS) with shoulder diameter 15, pin of frustum shape with base diameter $6 \mathrm{~mm}$, top diameter 4 $\mathrm{mm}$ and length $1.7 \mathrm{~mm}$. The base material sheets were clamped rigidly over the vertical bed from four sides to avoid vibration or displacement during processing.

Table 2 Selected process parameters for FSW of AA 6061 sheets with $2.1 \mathrm{~mm}$ thickness (defect free weld formation range) (Ramulu et al (2013))

\begin{tabular}{|c|c|c|c|}
\hline $\begin{array}{c}\text { Shoulder } \\
\text { diameter } \\
(\mathrm{mm})\end{array}$ & $\begin{array}{c}\text { Plunge } \\
\text { depth } \\
(\mathrm{mm})\end{array}$ & $\begin{array}{c}\text { Rotation } \\
\text { speed (rpm) }\end{array}$ & $\begin{array}{c}\text { Welding speed } \\
(\mathrm{mm} / \mathrm{min})\end{array}$ \\
\hline 15 & 2 & 1500 & 120 \\
\hline
\end{tabular}

\subsection{Mechanical tests}

\subsubsection{Micro hardness test}

Micro hardness profiles were taken across the welded joint, at different locations on the transverse cross-section of the joints. A $50 \mathrm{~g}$ load was used for the Vickers micro hardness measurements. Three trials were made and took averaged hardness value for each FSW condition along with base material. Figure 1 shows the schematic representation of micro hardness indents locations in transverse cross section of the FSW joints during hardness measurement.

\begin{tabular}{|c|c|c|}
\hline \multicolumn{3}{|c|}{ Transition zone Weld nugget Transition zone } \\
\hline 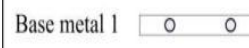 & $\begin{array}{lll}0 & 0 & 0\end{array}$ & $\begin{array}{lll}0 & 0 & \text { Base metal } 2\end{array}$ \\
\hline
\end{tabular}

Fig. 1 Schematic representation of micro hardness indents locations in transverse cross section of the FSW joints

\subsubsection{Tensile test}

The mechanical properties of base metal, FSW blanks and FSW blanks with only weld zone were measured using tensile tests as per ASTM-B557M. Tensile tests were performed at a nominal cross-head speed of $1 \mathrm{~mm} / \mathrm{min}$ and at room temperature on an INSTRON 8801 tensile testing machine and repeated thrice for each set to check the reproducibility. Failure from grip or slippage during testing was not observed. Whereas all FSW blanks and FSW blanks with only weld zone tensile samples were made parallel to the loading direction (longitudinal direction) only. So that in FSW blanks both weld and base metal deform during tensile testing. Similarly in the case of only weld zone FSW blanks specimens also. The mechanical properties like yield strength, ultimate tensile strength, total elongation, uniform elongation; strain hardening coefficient $(\mathrm{n})$ and strength coefficient $(\mathrm{K})$ values were evaluated as per the standard procedure after testing the samples till failure for base metal and FSW blanks of all FSW conditions. The load stroke behaviour obtained during testing was converted into engineering stress - strain and true stress - strain plot for evaluating the mechanical properties.

\subsubsection{Simulation of tensile test of Base metal, FSW blanks and only weld zone blank}

The tensile test simulation was performed using PAMSTAMP 2G, a commercial finite element code. The base material and weld zone model consisted of quadrilateral shell elements of the Belytschko-Tsay formulation. Mesh size of $1 \mathrm{~mm}$ was kept constant for the welded region and base metal. Hollomon's power law $(\sigma=$ $K \varepsilon^{n}$, where $K$ is the strength coefficient and $n$ is the strainhardening exponent) was used by verifying experimental tensile behavior of base metal, FSW sheets, and only welded sheet to simulation tensile behaviour and Hill's 1948 isotropic hardening yield criterion was used as the plasticity model. Friction coefficient ' $\mu$ ' was assumed to be 0.12 , and was kept constant throughout the simulations. This particular ' $\mu$ ' value closely simulates the dry friction condition existing at the sheet-punch interface in experiments. 


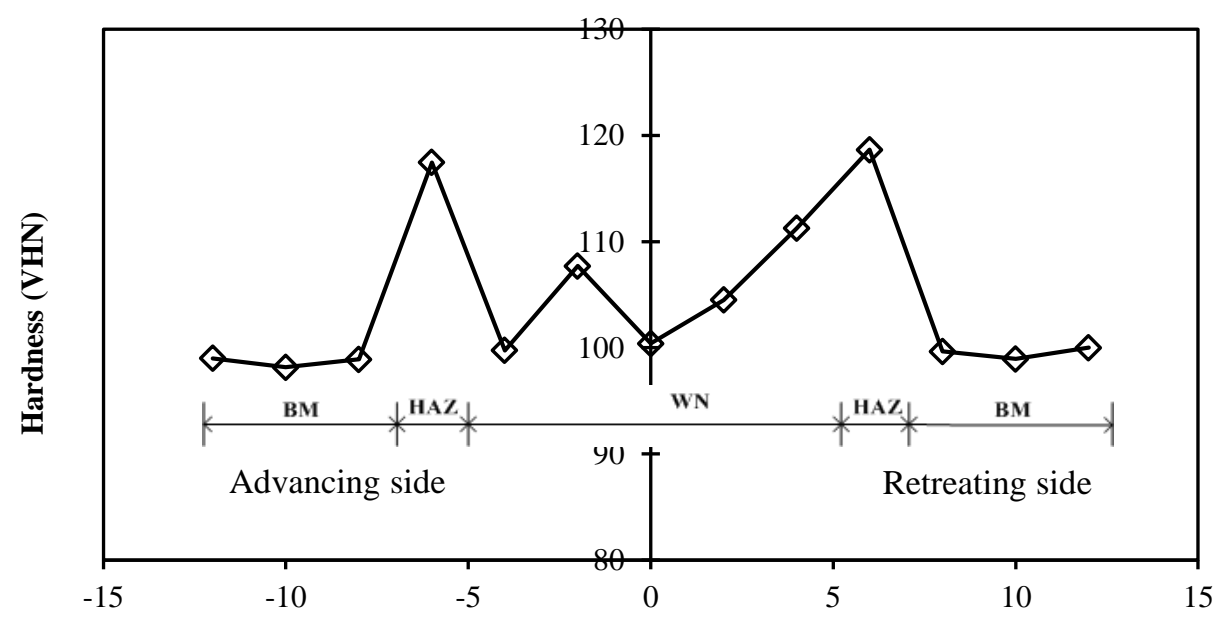

Distance from weld center (mm)

Fig. 2 Micro hardness profiles on the cross section of FSW joint

Table 3 Mechanical Properties

\begin{tabular}{|l|l|l|l|l|l|l|}
\cline { 2 - 7 } \multicolumn{1}{c|}{} & YS (MPa) & UTS (MPa) & UE $(\%)$ & TE $(\%)$ & $\mathrm{n}$ & K $(\mathrm{MPa})$ \\
\hline Base Metal & $267 \pm 3$ & $304 \pm 2$ & 9.2 & 11.2 & 0.1 & $414 \pm 10$ \\
\hline FSW sheet & $139 \pm 1$ & $237 \pm 4$ & 20.1 & 21.1 & 0.26 & $441 \pm 12$ \\
\hline Only Weld zone & $174 \pm 3$ & $270 \pm 13$ & 27.8 & 29.7 & 0.27 & $514 \pm 6$ \\
\hline
\end{tabular}

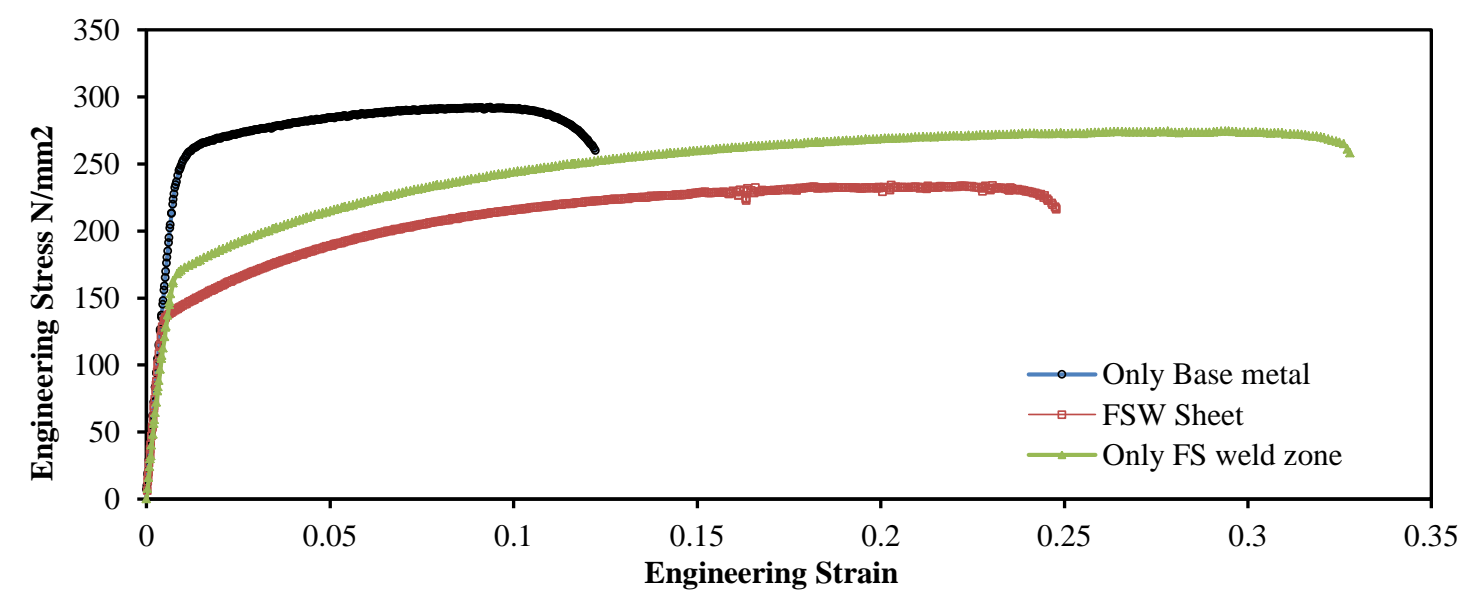

Fig.3 Engineering stress-strain behavior comparison among the base metal, FSW sheet and only FS weld zone

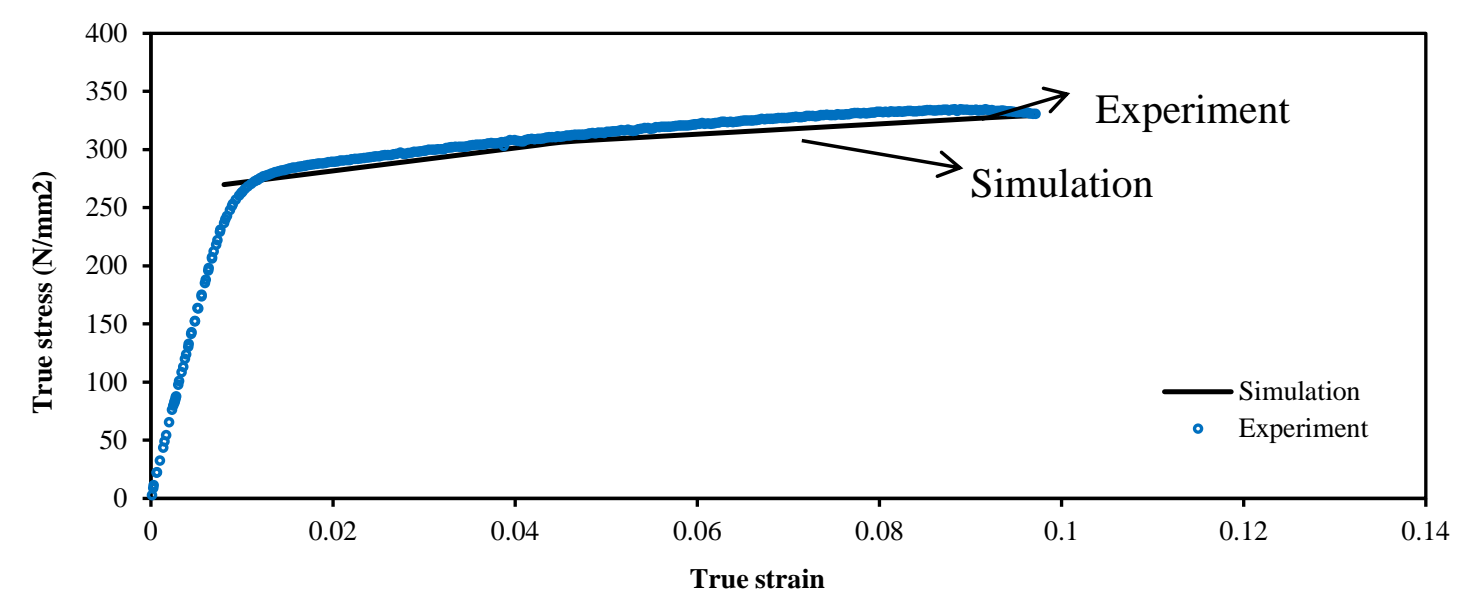

Fig.4 True stress-strain behavior comparison of base metal experimental data with simulation 


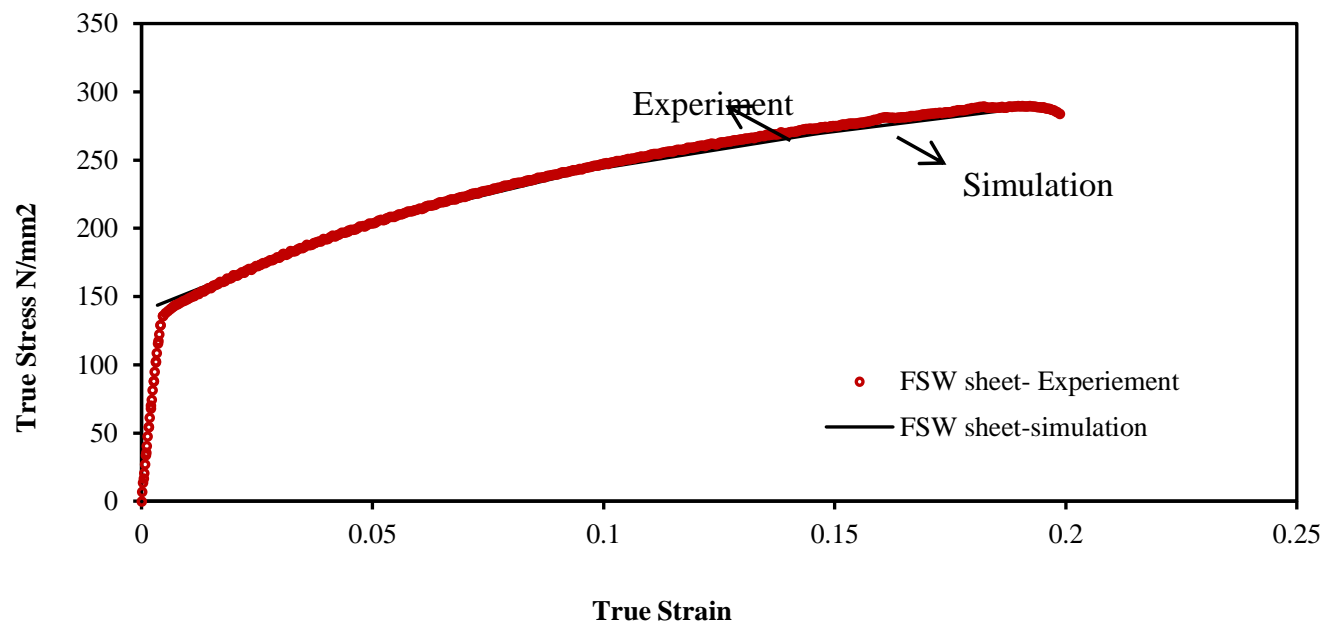

Fig.5 True stress- strain behaviour comparison of FSW sheet experimental data with simulation

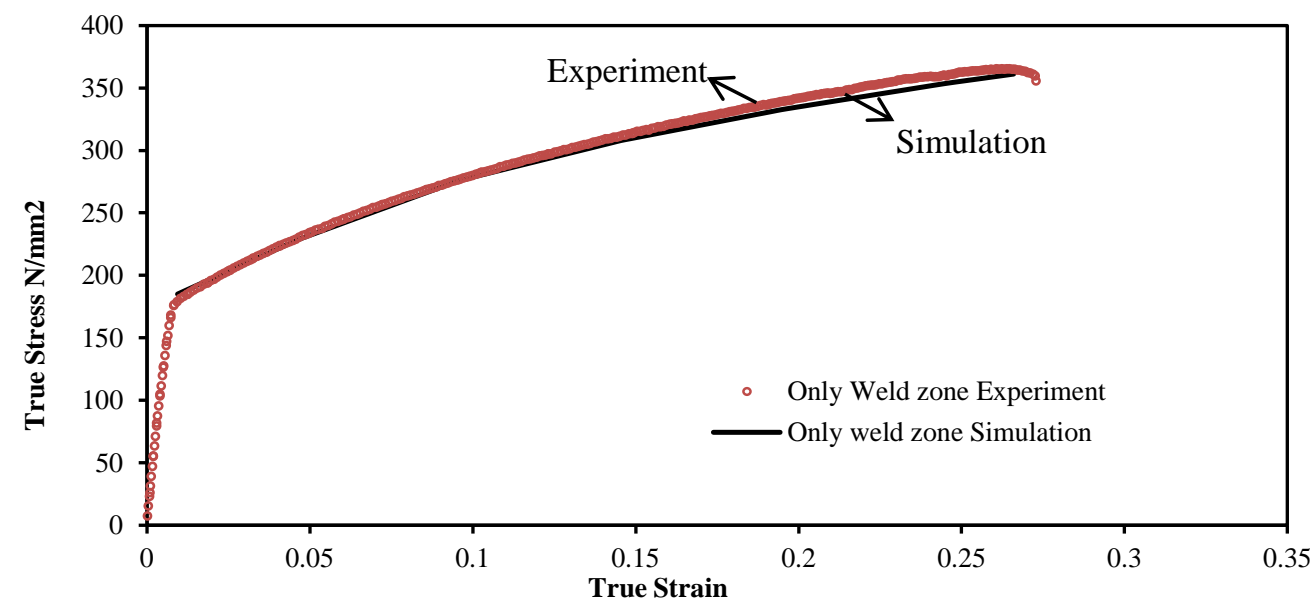

Fig.6 True stress- strain behaviour comparison of FS weld zone only experimental data with simulation

\section{Results and Discussion}

\subsection{Hardness behaviour}

The variation in hardness with distance from the center of the stir zone has been measured across the FS weld. Figure 2 shows the hardness profiles of FSW blank which is fabricated with tool shoulder diameters $15 \mathrm{~mm}$ at rotational speed of $1500 \mathrm{rpm}$, welding speed of 120 $\mathrm{mm} / \mathrm{min}$ and plunge depth of $1.95 \mathrm{~mm}$, starting from the base metal to the center of the weld to base metal, in the advancing and retreating directions. It is observed that the micro-hardness is high at transition zone (between base metal and weld zone) in retreating side of weld than other weld zones and minimum at nugget zone of both FSW blanks. Maximum hardness is found as 118. $65 \mathrm{VHN}$ at transition zone and minimum is $100 \mathrm{VHN}$ at nugget. The averaged micro hardness of the base material has been obtained as 104.6 VHN.

\subsection{Mechanical properties of base metal, FSW sheet and only weld zone}

The base material FSW sheet and only weld zone mechanical properties are evaluated. Table 3 summarizes obtained the mechanical properties of AA 6061 base material in the present work. It is found that strength point of view base has better strength than other; whereas only weld zone of FSW sheets has better uniform elongation and total elongation than the other two. FSW sheet and only weld zone of FSW sheet is compared only weld zone has better mechanical properties in all the aspects.

\subsection{Tensile behaviour of base metal, FSW sheet and only weld zone and comparison with simulation results}

The tensile behaviour of all three sheets has been observed and plotted the data corresponding to engineering stress and engineering strain as shown in Fig. 3. It is observed that yield and ultimate strength is more for the base metal as compared to other two whereas as uniform elongation and total elongation is more for only weld zone as discussed in the previous section and tabulated in Table 3 . From the Fig. 4-6 shows the experimental validation corresponding to true strain and true stress behaviour with simulation results. From the Fig 4-6 indicated that experimental results are coinciding with simulation results very well. This shows the accuracy level in the experimentation for tensile behaviour is ideally good.

The mechanical properties of all the sheets shows that due to FS welding ductility has been improved by which the 
formability of FSW sheets will be better than the base material.

\section{Conclusions}

The main aim of the present work is to investigate the tensile behaviour of base metal, FSW blanks and only weld zone of FSW sheet. The conclusions obtained from the present work are as follows.

1. Micro hardness showed a decrease, from the base material to the middle line of the FSW zone except at transition zone.

2. The un-welded blank has higher tensile properties and lesser elongation compared to FSW blanks in all FSW conditions.

3. The prediction results and experimental results are coincided very well with negligible error.

\section{Acknowledgement}

Perumalla Janaki Ramulu would like to thank Prof. Satish V. Kailas for his support during the experimental work at IISc Bangalore, and Prof. R. Ganesh Narayanan IIT Guwahati for permitting to use the testing facility.

\section{References}

R. S. Mishra, Z.Y. Ma, (2005), Friction stir welding and processing. Mater. Scie. and Engg. R, 50, 1-78.

M. Ghosh, K. Kumar, S. V. Kailas, A. K. Ray, (2010), Optimization of friction stir welding parameters for dissimilar aluminum alloys, Mater. and Desi., 31, 3033-3037.
S. Sato, H. Kokawa, (2001), Distribution of Tensile Property and Microstructure in Friction Stir Weld of 6063 Aluminum, Metall. and Mater. Trans. A, 32A, 3023-3031.

S. Lim, S. Kim, C. Lee, S. Kim, (2004), Tensile Behavior of Friction-Stir-Welded Al 6061-T651, Metall. and Mater. Trans. A, 35A, 2829-2835.

G. Buffa, L. Fratini, M. Merklein, D. Stau, (2007), Investigations on the Mechanical Properties and Formability of Friction Stir Welded Tailored Blanks, Engg. Materls, 344, 143-150.

A. Simar, Y. Brechet, B. De Meester, A. Denquin, T. Pardoen, (2008), Microstructure, local and global mechanical properties of friction stir welds in aluminium alloy 6005A-T6, Materls. Scie. and Engg. A, 486, 85-95.

L. Giles, K. Oh-ishi, A. P. Zhilyaev, S. Swaminathan, M. W. Mahoney, T. P. Mcnelley, (2009), The Effect of Friction Stir Processing on the Microstructure and Mechanical Properties of an Aluminum Lithium Alloy, Metall. and Mater. Trans. A, 40A: 104-115.

A. A. Zadpoor, J. Sinke, R. Benedictus, (2010), Global and Local Mechanical Properties and Microstructure of Friction Stir Welds with Dissimilar Materials and/or Thicknesses, Metall. and Mater. Trans. A, 41A, 3365-3378.

E. Cerri, P. Leo, X. Wang, J. D. Embury, (2011), Mechanical Properties and Microstructural Evolution of Friction-StirWelded Thin Sheet Aluminum Alloys, Metall. and Mater. Trans. A 42A, 1283-1295.

P. Janaki Ramulu, R. Ganesh Narayanan, Satish V. Kailas, Jayachandra Reddy, (2013), Internal defect and process parameter analysis during friction stir welding of Al 6061 sheets, Inter. Jour. of Adv. Manuf. Tech., 65, 1515-1528. 